\title{
LOS CENTROS DE GESTION EN EL CONTEXTO DE LA REFORMA DE LA FUNCION PUBLICA TERRITORIAL FRANCESA
}

\author{
POR \\ Pedro Soria Fernández-Mayorales
}

\begin{abstract}
SUMARIO: I. LA FUNCIÓN PÚBLICA TERRITORIAL FRANCESA: 1 Evolución reciente $y$ regulación legal. 2. El Estatuto de la función pública territorial: a) Los principios inspiradores de la Ley de 26 de enero de 1984 . b) Las reformas introducidas por la Ley de 13 de julio de 1987.- II. LOS CENTROS DE GESTIÓN DE LA FUNCIÓN PÚBLICA TERRITORIAL: 1. Introducción 2. Organización. 3. Régimen financiero. 4. Competencias: A) Competencias obligatorias. B) Competencias voluntarias.-5. Conclusión.
\end{abstract}

\section{LA FUNCION PUBLICA TERRITORIAL FRANCESA}

\section{Evolución reciente y regulación legal}

El actual proceso reformador de la función pública territorial viene enmarcado dentro del amplio movimiento de descentralización operado en Francia a partir de la Ley de 2 de marzo de 1982.

Desde el año 1981, Francia ha conocido una vasta reforma descentralizadora que le ha llevado a aumentar los poderes de todos los organismos integrantes de la Administración territorial, a través de un proceso de transferencia de competencias por parte del Estado a los Municipios, Departamentos y Regiones.

Es, pues, en el marco de esta operación descentralizadora donde hay que situar la evolución reciente en materia de función pública territorial. Como corolario de aquélla, se ha considerado necesario dotar a las Administraciones territoriales de una nueva función pública que acabase con los defectos inherentes a la anterior etapa (multitud de estatutos particulares, ausencia de salidas, mediocridad en las retribuciones, reclutamiento a menudo discrecional, etc,) y darle a los funcionarios un estatuto atractivo y moderno que acabase con el fenómeno de la estatización que se iba a producir a la larga en la vida de las colectividades locales, con la colonización por éstos de la función pública local.

Hasta 1983 no existía una auténtica función pública territorial, en la medida en que no existía una regulación unitaria para todo el personal que prestaba sus servicios en una Administración no estatal. Así, mientras los funcionarios municipales estaban sometidos a estatutos muy heterogéneos, los funcionarios de los Departamentos y de las Regiones carecían de un verdadero estatuto, 
quedando sometidos, en lo que concierne a los primeros, a una simple Circular del Ministerio del Interior, y en lo que respecta a los segundos, a reglas transitorias que los asimilaban a los funcionarios departamentales o a los del Estado, según los casos.

En este contexto indicado, y siendo intención del Estado dotar a los agentes de las colectividades territoriales de las mismas garantias que a sus propios funcionarios, se dictó la Ley del 13 de julio de 1983, sobre derechos y obligaciones de los funcionarios, $y$, posteriormente, la Ley de 26 de enero de 1984, conteniendo disposiciones estatutarias relativas a la función pública territorial, y que constituye en la actualidad el título III del Estatuto General de los Funcionarios (1).

\section{El Estatuto de la función pública territorial}

Como acabamos de indicar, dicho Estatuto está constituido básicamente por la Ley de 26 de enero de 1984, luego modifiçada por la Ley de 13 de julio de 1987, y cuyas repercusiones examinaremos más adelante.

No puede decirse que antes de la reforma nacida con la descentralización no existiesen los funcionarios territoriales como tales, pero ya hemos visto que éstos carecían de una unidad legislativa; o, si se quiere, hasta 1984 no se ha organizado -tardíamente- la función pública territorial.

\section{a) LOS PRINCIPIOS INSPIRADORES DE LA LEY DE 26 DE ENERO DE 1984}

La reforma introducida por esta Ley ha basculado, según ha reconocido ampliamente la doctrina francesa, sobre tres principios, que van a ser examinados a continuación.

1. El principio de unidad de la función pública territorial: esta unidad significa que se agrupan en un mismo estatuto a todos los agentes de las colectividades territoriales, y no sólo a los de los Municipios, Departamentos y Regiones, sino también a los integrantes de los organismos o instituciones públicos de ámbito territorial.

(1) El Estatuto de la Función Pública está constituido de la siguiente forma:

- Título I: Estatuto General, aplicable a todos los funcionarios (constituido por la citada Ley de 13 de julio de 1983).

- Título If: Estatuto de la Función Pública del Estado (constituido por la Ley de 11 de enero de 1984).

- Título III: Estatuto de la Función Pública Territorial (constituido por la citada Ley de 26 de enero de 1984, modificada por otra Ley de 13 de julio de 1987).

- Título IV: Estatuto de la Función Pública Hospitalaria (constituido por la Ley de 9 de enero de 1986). 
Esta unidad es, asimismo, condición indispensable para asegurar una auténtica movilidad entre los distintos funcionarios de las colectividades territoriales.

2. El principio de paridad entre la función pública territorial y la función pública del Estado: la paridad significa que los funcionarios de las colectividades territoriales tienen los mismos derechos y obligaciones que los funcionarios estatales. Esta paridad se traduce, además, en la existencia de una serie de garantías institucionales, tales como una identidad de remuneraciones entre grupos de funcionarios comparables, ejercicio de derechos sindicales, permisos idénticos, etc.

Esta paridad con la función pública del Estado se tradujo, asimismo, en la creación de cuerpos de funcionarios regidos por estatutos de carácter nacional, a semejanza de los funcionarios estatales.

3. El principio de especificidad de la función pública territorial: que no es otra cosa que la subsistencia de determinadas peculiaridades en la función pública territorial, a través de las cuales se intenta evitar una igualdad absoluta que pugnaría con el principio de autonomía reconocido a las colectividades territoriales. De esta exigencia de dotar a las colectividades territoriales de un mayor margen en la libre administración de sus competencias en materia de personal surge la idea de confiar la gestión de los funcionarios territoriales a los Centros de Gestión, que van a ser estudiados más adelante.

Una de las principales innovaciones de la Ley la constituye la separación del grado y del empleo. Hasta la aprobación de esta Ley, los funcionarios locales estaban regidos por el sistema de empleo, y no por el de carrera. Esto significaba que los funcionarios eran reclutados para ocupar un empleo concreto, de tal suerte que la supresión de éste implicaba el cese de aquél, a no ser que pudiese ser reclasificado en otro empleo.

Con el nuevo sistema instaurado por la Ley de 26 de enero de 1984, la supresión del empleo por una autoridad local no supone la separación del servicio del funcionario, ya que podrá ocupar otro empleo equivalente a su grado, o, en el caso de que no exista en su Administración de origen, se hará cargo de él el Centro de Gestión, que se encargará de buscarle otro empleo en una entidad territorial distinta.

En conclusión, podemos decir que la Ley de 26 de enero de 1984 constituye incontestablemente un avance en la instauración de una verdadera carrera administrativa para el personal de las colectividades territoriales. 
Respondiendo a las críticas procedentes de los gobernantes territoriales, que consideraban que la Ley de 1984 hurtaba determinadas competencias a las autoridades locales en materia de gestión de personal, la Ley de 13 de julio de 1987 ha tratado de introducir una cierta flexibilidad en estos temas, dando un poco más de responsabilidad a aquéllas autoridades, especialmente en materia de selección de su personal. Puede decirse que el edificio estatutario instituido por la Ley de 1984 se mantiene, pero se introducen en él algunas reformas, acentuando si cabe más aún la especificidad de la función pública territorial.

Una de las principales innovaciones introducidas por esta Ley consiste en la supresión de los cuerpos de funcionarios y su sustitución por los llamados "cuadros de empleos», en tanto que la organización en cuerpos subsiste para la Administración del Estado y la hospitalaria. Según dice la propia Ley, uun cuadro de empleos agrupa a los funcionarios sometidos al mismo estatuto particular, titulares de un grado que les da vocación para ocupar un conjunto de empleos». En definitiva, el abandono de los cuerpos y su sustitución por cuadros de empleos no es sino un reforzamiento del poder directivo local, puesto que cada colectividad gestiona los cuadros de empleos que ella ha creado, a diferencia de los cuerpos, que precisan de una gestión bajo una autoridad unitaria. Esto ha traído como consecuencia una restricción de las posibilidades de movilidad entre los funcionarios territoriales, y entre éstos y los estatales.

Una mayor maniobrabilidad para las autoridades locales se plasma, asimismo, en la extensión del procedimiento contractual para cubrir los puestos vacantes o en la libre selección del personal, a excepción hecha de los municipios y establecimientos municipales obligatoriamente afiliados a un Centro de Gestión.

Podemos concluir diciendo que la Ley de 13 de julio de 1987 ha supuesto la instauración del principio de gestión de los funcionarios territoriales por cada autoridad local, rechazando toda intervención exterior y todo automatismo en los procedimientos de administración del personal. Con estas medidas se produce una restricción en el principio de carrera, volviendo en parte al sistema de empleo anterior, si bien con determinadas garantías que entonces no existían. Esta postura del legislador va a tener sus repercusiones en el contenido y atribuciones de los Centros de Gestión, que van a ver reducidas sus competencias respecto a las que les atribuía la Ley de 1984. 


\section{LOS CENTROS DE GESTION DE LA FUNCION PUBLICA TERRITORIAL}

\section{Introducción}

Los Centros de Gestión de la función pública territorial son creados a raíz de los nuevos principios introducidos por la Ley de 26 de enero de 1984, si bien en determinados casos no se trata sino de recoger las atribuciones -aumentadas, claro está- de los antiguos Sindicatos Intermunicipales de Personal (2).

Juntamente con los Centros de Gestión, la Ley de 1984 creó el Centro Nacional de la Función Pública Territorial, con misiones similares a aquéllos, pero relativas a los funcionarios del grupo $\mathrm{A}$ $y$ algunos del grupo B (3), especialmente en materia de formación. Su estudio se deja fuera del presente trabajo por obvias razones, bastando con la cita aquí de su existencia.

Como ya hemos adelantado más atrás, la Ley de 13 de julio de 1987 ha mermado las atribuciones de los Centros de Gestión, especialmente en materia de selección, cambio y avance de grado de los funcionarios territoriales, como contrapartida al aumento de poder de los representantes políticos locales.

\section{Organización}

Los Centros de Gestión son establecimientos públicos de carácter administrativo que gozan de autonomía jurídica y financiera. Tienen ámbito departamental, si exceptuamos los llamados de la «Pequeña Corona» y de la "Gran Corona», que agrupan a varios Departamentos (4).

La afiliación a los Centros de Gestión es obligatoria para los municipios y establecimientos públicos municipales que empleen menos de 250 funcionarios a tiempo completo; en otro caso, la

(2) La legislación local francesa prevé la creación voluntaria de Sindicatos Intermunicipales para la prestación de servicios a los municipios asociados. Serían el equivalente de nuestras Mancomunidades.

(3) Los funcionarios franceses se agrupan en cuatro categorias: A, B, C y D, según se requiera para su acceso titulación superior, bachillerato, estudios de primer ciclo o certificado de estudios primarios, respectivamente. Estas categorías se corresponden aproximadamente con nuestros grupos $A, C, D$ y $E$.

(4) El Centro Interdepartamental de la «Pequeña Corona»-llamado así por la configuración física de los Departamentos que lo integran, que rodean a París como una especie de corona o circulo envolvente- comprende los Departamentos de Hauts-de-Seine, Seine-Saint-Denis y Valde-Marne; el Centro Interdepartamental de la "Gran Corona»-llamado así por los mismos motivos que el anterior, sólo que éste cubriendo un área mayor y más alejada de Paríscomprende los Departamentos de Essone, Val-d'Oise e Yvelines.

REVISTA DE ESTUDIOS.-7 
afiliación es meramente facultativa. También pueden afiliarse voluntariamente los Departamentos, las Regiones y los establecimientos públicos de ellos dependientes (5).

$\mathrm{Si}$ tenemos en cuenta que, de los aproximadamente 36.000 municipios franceses, el 90 por 100 tiene menos de 2.000 habitantes, podremos fácilmente tener una idea del nivel de afiliación obligatoria a los Centros de Gestión; si bien este dato no es determinante en cuanto al número de funcionarios bajo la égida de los Centros ya que, lógicamente, los municipios con mayor volumen de efectivos de personal no están obligatoriamente afiliados a ellos.

De todas formas, este dato si sirve para poner de relieve cuál es la dirección que se ha querido imprimir a estos organismos públicos, concebidos principalmente como ayuda y orientación para aquellos que más las necesitan, es decir, los pequeños municipios.

Cada Centro se encuentra regido por un Consejo de Administración, al frente del cual se halla un Presidente elegido por el conjunto de los representantes que componen aquél, y que a su vez son elegidos entre los Alcaldes y Consejeros municipales de los Ayuntamientos del Departamento donde se encuentra el Centro de Gestión, a través de una votación en la que a la hora de atribuir los votos se tiene en cuenta el número de funcionarios del Ayuntamiento respectivo. Los representantes del Departamento y de la Región, por su parte, son designados por el Consejo General y por el Consejo Regional, respectivamente, entre sus miembros.

El mandato normal de los miembros del Consejo de Administración coincide con el de sus cargos en las respectivas Administraciones, a excepción de los representantes de los Departamentos, que expira a los seis años.

El Consejo de Administración es el órgano de dirección del Centro y en tal sentido se encarga de fijar las líneas orientadoras del mismo y de tomar las decisiones concernientes a su funcionamiento (adquisición de bienes; conciertos de préstamos; fijación de los efectivos personales del Centro; señalamiento de las tarifas a pagar por los organismos afiliados, etc.).

Por su parte, el Presidente del Centro se encarga de preparar y ejecutar las decisiones del Consejo de Administración; además, se ocupa de la dirección técnica, administrativa y financiera del Centro.

En cuanto al personal propiamente dicho, existe un Director del Centro y un determinado número de funcionarios que se ocupan de

(5) Hay que hacer constar que el Municipio y el Departamento de París, así como sus establecimientos públicos, gozan de un «status» especial que les hace no estar vinculados ni a un Centro de Gestión ni al Centro Nacional de la Función Pública Territorial. 
los diferentes servicios que el Centro presta a sus entidades afiliadas.

Para finalizar este apartado, interesa reseñar que los actos dictados por los Centros de Gestión son ejecutivos, debiendo ser comunicados al Comisario de la República (Prefecto), quien los impugnará ante un Tribunal Administrativo si los considera contrarios a la legalidad.

\section{Régimen financiero}

Como cualquier Ente público, los Centros de Gestión cuentan con un presupuesto donde se recogen sus ingresos y gastos.

Para hacer frente a sus necesidades los Centros de Gestión se nutren fundamentalmente de las cuotas obligatorias que deben pagar las colectividades a ellos afiliadas. Esta cotización se fija en un porcentaje sobre la masa de las remuneraciones pagadas a los respectivos agentes de las colectividades locales. Dicho porcentaje es establecido por el Consejo de Administración, con un límite máximo que no puede ser rebasado.

Para el desempeño de aquellas funciones que la Ley no atribuye como obligatorias a los Centros, y que éstos prestan facultativamente, se fija una cotización adicional a pagar por las colectividades asociadas, o bien, en su caso, se financian tales funciones a través de un convenio establecido al efecto.

Además de estos ingresos, los Centros pueden tener también otras fuentes de financiación comunes a cualquier organismo público, tales como subvenciones, donativos, empréstitos, etc.

Las funciones contables del Centro son ejercidas por un funcionario nombrado por el Ministro de Economía.

\section{Competencias}

Como ya hemos indicado anteriormente, las competencias de los Centros de Gestión se han visto reducidas a la entrada en vigor de la Ley de 13 de julio de 1987; no obstante, dichos Centros ejercen una serie de funciones de gran importancia que trascienden. en ocasiones, las meras de gestión de personal.

Para lograr una visión más clara de su labor, vamos a dividir el estudio de sus competencias en dos apartados, según se trate de competencias obligatorias o impuestas por la Ley a todos los Centros, o de competencias facultativas, que son aquellas que libremente pueden prestar por decisión de sus asociados. 


\section{A) COMPETENCIAS OBLIGATORIAS}

a) Organización de pruebas selectivas y exámenes profesionales: Esta función se lleva a cabo para los funcionarios de los grupos $C$ y $D$, así como para las categorías del grupo $B$ que no dependan del Centro Nacional de la Función Pública Territorial.

En el caso de colectividades no asociadas, a las que la Ley atribuye la facultad de seleccionar a su propio personal, formará parte del Tribunal de selección un representante del Centro de Gestión; no obstante, estas colectividades pueden, mediante convenio con el Centro, delegar en éste las facultades que legalmente les corresponden. En el supuesto de que opten por seleccionar a su personal las colectividades que gozan de esta prerrogativa, el Centro de Gestión prestará su ayuda técnica para la organización de las pruebas a aquellas que lo soliciten.

b) Gestión de la carrera administrativa: Asimismo, para los funcionarios citados en el apartado anterior. Con tal motivo, el Centro de Gestión lleva un «dossier» individual por cada funcionario donde se anotan todos los datos relativos a su carrera administrativa (nombramiento; ascenso de escalón y de grado (6); excedencia; permisos; permutas; sanciones disciplinarias, etc.).

Normalmente, y dada la constante puesta al día del «dossier» de cada funcionario, estas tareas son informatizadas. Este "dossier» tiene un carácter reservado, y únicamente puede ser consultado por el propio interesado o por la autoridad de quien depende el funcionario.

c) Asegurar el funcionamiento de determinados órganos funcionariales: El Centro de Gestión tiene por misión asegurar que determinados órganos colegiados previstos legalmente funcionen dentro de su seno y ajusten su actuación a sus normas estatutarias, tales como:

- Las Comisiones Paritarias, que son órganos consultivos integrados a partes iguales por representantes de los funcionarios y por miembros electivos de las colectividades locales. Las Comisiones Paritarias deben informar con carácter previo una serie de decisiones relativas a la

(6) La carrera administrativa de los funcionarios locales comprende un ascenso de escalón $y$ un ascenso de grado.

El ascenso de escalón tiene lugar en función de la antigüedad y de la capacidad profesional, conjuntamente. El ascenso de escalón se traduce en una mejora de sueldo.

El ascenso de grado tiene lugar por vía de formación profesional, de examen profesional o de concurso. En los dos primeros casos, el funcionario tiene que inscribirse en un tablón anual de ascenso, cuya publicidad es asegurada por el Centro de Gestión. El ascenso se dicta por la autoridad territorial y está supeditado a la aceptación por parte del funcionario del empleo que le sea asignado en su nuevo grado. 
situación del funcionario $y$ a su promoción profesional (ascenso de grado y de escalón, licenciamiento en caso de insuficiencia profesional, etc.).

- Los Consejos de Disciplina, órganos asimismo consultivos cuyo parecer debe ser oído en todos los supuestos de sanciones a funcionarios que revistan una cierta gravedad. Estos Consejos de Disciplina están compuestos por miembros de las Comisiones Paritarias, en la misma proporción que éstas, y su informe no es vinculante para la autoridad territorial que debe imponer la sanción.

- Los Comités Técnicos Paritarios, compuestos por representantes de las colectivades y del personal, a partes iguales. Su misión consiste en dar su parecer en determinadas cuestiones relativas a la organización de la Administración y de sus condiciones de funcionamiento.

d) Publicidad de las creaciones de empleos y de sus vacantes: En esta materia, la Ley de 13 de julio de 1987 es bastante tajante al afirmar que todas las creaciones de nuevas plazas, así como de las vacantes que existan, deben ser comunicadas al Centro de Gestión previamente a su provisión, so pena de nulidad de pleno Derecho de los nombramientos efectuados obviando esta obligación.

De esta manera, el Centro procede a constituir una bolsa de empleo a fin de facilitar la información sobre todas las vacantes existentes de personal local y establecimientos públicos de ellos dependientes. Dicha obligación es aplicable tanto si se trata de colectividades afiliadas como de no afiliadas.

e) Toma a cargo de los funcionarios privados de empleo: Como ya hemos visto anteriormente, la nueva regulación de la función pública local introdujo la regla de la separación del grado y del empleo, de tal forma que cuando una colectividad territorial decide suprimir un empleo, el funcionario en vez de quedar sin trabajo, como ocurría con anterioridad, puede ocupar otros empleos correspondientes a su grado. Ahora bien, en tanto esto no se produce, el funcionario privado de empleo es tomado a su cargo por el Centro de Gestión, quien se encarga de buscarle un nuevo empleo adecuado a su grado.

Pero para que esta situación no sea tan gravosa para los Centros, que deberían soportar la carga de cualquier funcionario privado temporalmente de su empleo con el consecuente montante económico que ello conlleva, se ha previsto por la ley que la colectividad de la que el funcionario procede, y que le ha privado de su empleo, contribuya económicamente con una aportación mientras dura esta situación provisional de paro para el funcionario. 
También pueden darse otros supuestos de toma a cargo por el Centro de Gestión. Así ocurre, por ejemplo, en los casos de empleos funcionales (7), que pueden ser cubiertos libremente, o en casos de excedencia de larga duración no seguida de incorporación al trabajo en razón de no existir puesto vacante.

En todos estos supuestos, es indiferente que la colectividad de donde procede el funcioanrio esté o no afiliada al Centro de Gestión.

La contribución económica que soporta la colectividad local varía en función de que se trate o no de establecimiento asociado, $y$ en ambos casos del tiempo en que el funcionario se encuentre en esa situación (a mayor tiempo, menor contribución económica).

En el supuesto de que el funcionario rechazase tres ofertas de empleo propuestas por el Centro, perdería definitivamente su condición de funcionario y quedaría en situación de cesante, a no ser que pudiera acogerse a la jubilación por edad.

f) Reclasificación de funcionarios no aptos: Los Centros de Gestión tienen por misión proceder a una nueva clasificación de aquellos funcionarios que han sido declarados no aptos para el desempeño de sus funciones. En tal caso, dichos funcionarios pueden cumplir otras funciones para las que estén capacitados. Esta reclasificación puede producirse respecto de un cuadro de empleo de igual o inferior categoría por diversos medios (oposición, promoción interna, integración, etc.)

En el supuesto de que la nueva clasificación conlleve la posesión de un grado inferior al de origen, el funcionario conservará en todo caso un índice igual al de su anterior empleo. La carga financiera resultante será de cuenta del Centro de Gestión.

g) Colaboración con la Caja Nacional de Jubilaciones: Los Centros de Gestión aportan su colaboración a la Caja Nacional de Jubilaciones de los Agentes de las Colectividades Territoriales (C.N.R.A.C.L.). La misión confiada aquéllos consiste en constatar, por delegación de esta institución, la duración de los servicios cumplidos por el personal, así como en gestionar obras sociales en favor de los jubilados.

A través de los Centros de gestión, las colectividades locales solucionan los problemas relativos a las pensiones de sus funcionarios, siendo, pues, el papel de aquéllos el de intermediarios entre ambos organismos, a fin de acercar a los afectados la actividad de la C.N.R.A.C.L.

(7) Se denominan así determinados puestos de trabajo que no gozan de una seguridad absoluta de empleo, sino que son cubiertos libremente por la autoridad territorial, que puede cesarlos en cualquier momento. En general, se cubren por este procedimiento los puestos más altos de la función pública territoriail. 
h) Gestión de su propio personal: Obviamente, los Centros de Gestión, como organismos que gozan de personalidad jurídica propia, se encargan de todo lo referente al personal que presta en ellos sus servicios (selección, retribución, etc.); inclusive se comprende aquí al personal tomado a su cargo por el Centro, al que nos hemos referido en el apartado e) precitado.

\section{B) COMPETENCIAS VOLUNTARIAS}

El artículo 25 de la Ley de 13 de julio de 1987 otorga a los Centros de Gestión la posibilidad de prestar cualquier otro servicio que tenga relación con el personal de las colectividades territoriales y establecimientos afiliados, siempre y cuando así se acuerde por éstos. Lógicamente, tales servicios conllevan el pago adicional de unas cantidades que se fijan por el Consejo de Administración del Centro por cada uno de los servicios que se prestan.

Con carácter no limitativo se van a enumerar a continuación algunas de estas competencias.

a) Sustitución temporal de funcionarios: Se trata de un servicio que tiene por finalidad reemplazar a aquellos funcionarios titulares que por uno u otro motivo deben ausentarse temporalmente de la Administración donde prestan su labor. Esta competencia se ejerce normalmente en el ámbito de los pequeños municipios, en los que la ausencia del Secretario -a veces, el único funcionario de la Corporación- plantea verdaderos problemas.

Para cumplir su misión, el Centro envía a los Ayuntamientos de estos pequeños municipios a un funcionario cualificado que se encargará de desempeñar las tareas del ausente hasta el regreso de éste. Este servicio suele ser satisfecho por la colectividad interesada en virtud de un precio/hora fijado de antemano.

b) Gestión de obras y servicios sociales: Dentro de este amplio apartado es de destacar la existencia en algunos Centros de Gestión de un servicio de Medicina Profesional, que asegura a las colectividades locales una serie de prestaciones, variables según los medios y necesidades, entre las que podemos citar, a título de ejemplo: reconocimiento médico anual, vacunaciones, inspección de locales, etc.

c) Suscripción de contratos de seguros: Estos contratos garantizan contra los riesgos financieros derivados de determinadas situaciones en que pueden encontrarse los funcionarios y que dan lugar al pago de unas cantidades en concepto de indemnización o ayuda (muerte en acto de servicio, enfermedad profesional, accidentes, etc.). En estos casos, los Ayuntamientos y establecimientos públicos afiliados deben reembolsar al Centro de Gestión el montante de las primas de seguro pagadas por éste. 
d) Asesoramiento jurídico: Nos encontramos ante uno de los servicios más importantes que prestan los Centros de Gestión, aunque no esté directamente relacionado con la materia de personal. Como es fácil deducir, se trata de un servicio dirigido principalmente a las pequeñas colectividades locales, las cuales carecen de los más elementales niveles de asesoramiento por faltarles precisamente los funcionarios con conocimientos suficientes para tal menester.

Un gabinete de asesoramiento jurídico se encarga de prestar su asistencia a las autoridades locales en todas aquellas cuestiones de la vida municipal que puedan afectarles, y que puede llegar incluso hasta la defensa en juicio. Esta ayuda se realiza a través de diversos medios, ya por escrito, o bien directamente mediante consulta telefónica. También se facilita información a los asociados a través de la edición, en algunos casos, de revistas o boletines que recogen las últimas novedades en materia de Administración Territorial (legislación, doctrina del Consejo de Estado, etc.). Algunos Centros de Gestión cuentan con un banco de datos informático que está abierto a las entidades afiliadas, y en el que se recoge una amplia documentación sobre aspectos estatutarios de la función pública territorial (estudios jurídicos, legislación, jurisprudencia, prensa, etcétera).

e) Servicio informático: Además del citado anteriormente, los Centros que cuentan con los medios materiales necesarios para ello, ofrecen a los asociados la posibilidad de asumir una serie de trabajos de tipo rutinario que el uso de la informática simplifica sobremanera, descargando así a los pequeños Ayuntamientos, sobre todo, de esta clase de tareas para las que posiblemente no disponen de los medios adecuados. Entre aquéllos pueden citarse:

- La confección de nóminas del personal.

- La gestión del fichero electoral.

- La elaboración de recibos de agua.

f) Otros servicios: Sin ánimo de ser exhaustivos, podemos citar los siguientes:

- Asesoramiento técnico a los pequeños Ayuntamientos para la proyección, ejecución y dirección de obras de urbanismo.

- Edición de boletines informativos.

- Organización de reuniones de trabajo y conferencias, etc.

\section{Conclusión}

Como acabamos de ver, muchas e importantes son las funciones que cumplen los Centros de Gestión, y no ya sólo en los ámbitos estrictos de la materia funcionarial. De todas formas, como 
ésta es la que a nosotros nos interesa, intentaremos extraer aquí unas sucintas conclusiones que sirvan para poner de relieve las peculiaridades de estos organismos públicos desconocidos para nosotros:

a) Los Centros de Gestión nacieron como una necesidad del nuevo régimen estatutario creado en Francia con la Ley de 26 de enero de 1984, surgido a su vez del movimiento descentralizador de la organización administrativa local, con la finalidad inicial de gestionar los nuevos «cuerpos» de la función pública territorial.

b) Con la entrada en vigor de la Ley de 13 de julio de 1987 , que modifica la de 26 de enero de 1984 en el sentido de dotar de mayor autonomía a los gobernantes locales en la gestión de su personal, los Centros de Gestión han visto reducidas sus competencias obligatorias; no obstante, la Ley les dota las misiones de:

- Facilitar a las colectividades territoriales su ayuda en la administración del personal para algunos asuntos que desbordan las posibilidades de aquéllas.

- Garantizar a los funcionarios territoriales la estabilidad en su empleo en los supuestos en que se ven privados del mismo por sus colectividades de origen.

$Y$ para finalizar, una breve consideración final con relación a nuestro país.

En los actuales momentos que atraviesa la Administración local en España -donde se ha asentado con firmeza el principio constitucional de autonomía- es difícil pensar que puedan crearse aqui unos organismos públicos semejantes, con las competencias que tienen los Centros de Gestión en Francia. Alguna que otra función similar, sobre todo en materia de asesoramiento jurídico $y$ financiero, cumplen las Diputaciones Provinciales o Comunidades Autónomas uniprovinciales con los servicios de asistencia a los municipios, pero se está lejos de llegar a esa "dejación» de atribuciones en materia de personal en favor de un organismo distinto al propio Ayuntamiento interesado. En cualquier caso, hay que destacar los efectos positivos que, en nuestra opinión, una tal existencia de esos organismos podrían reportar a la Administración local española: independencia en la selección del personal, mayor objetividad en la gestión de la carrera del funcionario, instauración de reglas o principios comunes para todos los funcionarios pertenecientes a cuerpos o escalas idénticos, aplicación efectiva de la movilidad, etcétera.

Por último, hay que hacer notar el aspecto, para nosotros novedoso, de la financiación de los Centros de Gestión por los propios Ayuntamientos y organismos públicos asociados, lo que 
supone entender la actividad administrativa bajo un prisma distinto al de la mera actividad de subvención que se suele aplicar en España, dejando en manos de la entidad local la responsabilidad de asumir consciente y voluntariamente la recepción de una serie de servicios cuyo mantenimiento corre de su cuenta.

\section{BIBLIOGRAFIA UTILIZADA}

I. Libros.

Código Administrativo. Ed. Dalloz, París, 1987.

Serge Salon y Jean Charles Savignac: La función pública. Ed. Sirey, París, 1985.

Función Pública y Descentralización. Prensas Universitarias de Lille, 1987. Los Ayuntamientos franceses de hoy. Ed. PUF, París, 1986.

\section{Revistas}

Varios autores. "Los regímenes de función pública en Francia y España». Revista Francesa de Administración Pública, núm. 38, 1986.

JACQUES BOURDON: "La función territorial: un nuevo equilibrio entre la carrera y el empleo». Revista Francesa de Derecho Administrativo, núm. 3, 1988.

III. Otra documentación.

Boletines informativos y documentación diversa de los Centros de Gestión siguientes:

- Centro Interdepartamental de Gestión de la «Pequeña Corona» de la Región de lle-de-France (París).

- Centro Interdepartamental de Gestión de la «Gran Corona» de la Región de lle-de-France (Versailles).

- Centro Departamental de Gestión de los Pirineos Atlánticos (Pau).

Apuntes del curso «La Administración Local en Francia», seguido en el Instituto Internacional de Administración Pública (París) durante la primera quincena del mes de noviembre de 1988. 
REALA-1989, núm. 243. SORIA FERNANDEZ-MAYORALES, PEDRO. LOS CENTROS DE GESTION E...

REALA-1989, núm. 243. SORIA FERNANDEZ-MAYORALES, PEDRO. LOS CENTROS DE GESTION E... 